\title{
REDES DE RELAÇõES INDÍGENAS NO BRASIL CENTRAL: UM PROGRAMA DE PESQUISA
}

ANDRÉ DEMARCHI ${ }^{1}$

UFT

ODILON MORAIS ${ }^{2}$

UFT

RESUMO: $O$ presente artigo apresenta algumas reflexões iniciais de uma pesquisa em andamento sobre as redes de relações sociais (econômicas, identitárias, cerimoniais, visuais, políticas) criadas e alimentadas pelos diversos povos indígenas localizados na área etnográfica Tocantins-Xingu, também conhecida na etnologia ameríndia como a região do Brasil Central. As principais metas de nossa proposta de revisitar os Jê segundo essa abordagem contemporânea são: 1) o mapeamento e a compreensão das redes de relações existentes entre os diferentes povos Jê; 2) a reinserção dos Jê no cenário comparativo da etnologia das terras baixas sul-americanas; 3) O preenchimento de uma lacuna na proficua etnologia jê, no que tange ao tema das redes de relações e dos sistemas regionais ameríndios.

PALAVRAS-CHAVE: redes de relações; etnologia jê; Brasil Central.

ABSTRACT: This article presents some initial reflections of an ongoing research on the networks of social relations (economic, identity, ceremonial, visual, political) created and articulated by the various indigenous peoples located in the ethnographic area TocantinsXingu, also known in Ethnology as Central Brazil. The main goals of our proposal to revisit the Ge according to this contemporary approach are: 1) mapping and understanding of the relationship networks among different peoples $\mathrm{Ge} ; 2)$ the reintegration of $G e$ in the comparative scenario of the ethnology of the South American lowlands; 3) fill a gap in fruitful ethnology Jê, with respect to the issue of network relations and Amerindians regional systems.

KEYWORDS: relationship networks; Ge Ethnology; Central Brazil.

\footnotetext{
1 Doutor em antropologia pelo Programa de Pós-Graduação em Sociologia e Antropologia da Universidade Federal do Rio de Janeiro. É professor e pesquisador na Universidade Federal do Tocantins, onde leciona no curso de Ciências Sociais e no Programa de Pós-Graduação em Comunicação e Sociedade. Realiza pesquisas com os povos Mebengôkre-Kayapó e Apinajé. O desenvolvimento desta pesquisa contou com benefícios do Programa Novos Pesquisadores da UFT (PROPESQ/UFT). E-mail: andredemarchi@gmail.com.

${ }^{2}$ Doutorando em antropologia pelo Programa de Pós-Graduação em Antropologia da Universidade de Brasília. É professor e pesquisador na Universidade Federal do Tocantins. Realiza pesquisas com os povos Xerente e Apinajé. E-mail: odilonmorais@uft.edu.br .
} 
André Demarchi e Odilon Morais - Redes de relações indígenas no Brasil Central...

\section{Apresentação}

Os povos indígenas falantes de diferentes línguas pertencentes à família linguística Jê estão tradicionalmente estabelecidos na Área Etnográfica Tocantins-Xingu (MELATTI, 2011 b). Em sua diversidade, eles são talvez os povos mais bem-conhecidos na literatura etnográfica das terras baixas sul-americanas, não só pelo longo processo de ocupação colonial da região, iniciado no começo do século XVIII, como também pela quantidade (e qualidade) de monografias escritas a partir da segunda metade do século XX sobre vários dos grupos indígenas (Krahô, Xerente, Apinajé, Canela, Kayapó, Gavião, Krikati, Suyá, Karajá, Xavante) que ali vivem atualmente.

Ao revisar a literatura etnográfica sobre estes povos, percebe-se, porém, um baixo rendimento analítico no que se refere ao tratamento das redes de relações estabelecidas entre os grupos indígenas da região, contrastando com $\mathrm{o}$ intenso investimento descritivo e comparativo em aspectos do parentesco, da organização social e da cosmologia ${ }^{3}$, ou mesmo referente ao estudo do contato interétnico. Nesta chave, por exemplo, os dados sobre o que se convencionou chamar de "relações intertribais" aparecem como resíduos etnográficos praticamente inexplorados.

Entre os Jê e, principalmente, nos estudos desenvolvidos nos anos de 1960 e 1970 pelos integrantes do Projeto Harvard-Brasil Central4,

\footnotetext{
${ }^{3}$ Para uma análise comparativa monumental de praticamente toda a bibliografia Jê sobre esses e outros temas ver Coelho de Souza (2002).

${ }^{4}$ O Projeto Harvard-Museu Nacional ocorreu no período de 1962 a 1967 e foi realizado através de um convênio entre a universidade americana e o Museu Nacional de Antropologia, tendo como coordenadores os antropólogos David Maybury-Lewis e Roberto Cardoso de Oliveira. O projeto foi instituído com o intuito de investigar in loco algumas das problemáticas apresentadas pelas monografias de Nimuendaju, sobretudo aquelas referentes à organização social e ao funcionamento das organizações dualistas. Esta última problemática foi herdada diretamente de Lévi-Strauss. Um dos principais objetivos do Projeto era estabelecer uma pesquisa comparativa das sociedades jê através de uma série de pesquisas etnográficas individuais, cobrindo boa parte dos grupos jê e ainda acrescentando a eles os Bororo, por razões de semelhança, e os Nambikwara, porque colocavam também o problema do dualismo, tal como formulado por Lévi-Strauss (COELHO DE SOUZA, 2002). Contudo, foram deixados de fora do projeto os grupos meridionais ou jê do sul, Xokleng e Kaingang, considerados extintos no contexto do projeto. Sob a coordenação geral de Maybury-Lewis, que estudou os Xerente e os Xavante, a equipe contava, pelo lado estadunidense, com Terence Turner e Joan Bamberger, que estudaram os Kayapó; Jean Carter Lave, que estudou os Krikati; Cristopher Crocker, estudioso dos Bororo e, alguns anos depois, Anthony Seeger, que realizou pesquisas entre os Suyá. Do lado brasileiro, fechavam a equipe do projeto Roberto DaMatta,
} 
André Demarchi e Odilon Morais - Redes de relações indígenas no Brasil Central...

privilegiou-se descrições etnográficas circunscritas aos grupos étnicos e suas relações internas - o que de certa forma continua reverberando na produção recente. Diferentemente, nos estudos sobre outras regiões etnográficas (Noroeste Amazônico, Alto Xingu, Arawak subandinos, Guianas), destacou-se desde muito cedo a importância das redes supralocais de aliança político-matrimonial e de trocas simbólicas (ALBERT, 1985; GALLOIS, 2005; RAMOS, 1980; VIVEIROS DE CASTRO, 2002), privilegiando os nexos de relações tecidas entre os coletivos indígenas de regiões específicas.

O presente artigo apresenta algumas reflexões iniciais de um programa de pesquisa ${ }^{5}$ (em andamento) sobre as redes de relações sociais, econômicas, identitárias, cerimoniais, visuais e políticas criadas e alimentadas pelos diversos povos indígenas localizados na área etnográfica Tocantins-Xingu, também conhecida na etnologia ameríndia como a região do Brasil Central. O presente programa de pesquisa visa recuperar o espírito comparativo do Projeto Harvard-Brasil Central, tomando como foco de comparação as diferentes redes de relações tecidas pelos diversos povos indígenas Jê (ou não Jê) situados na área etnográfica Tocantins-Xingu. Os principais objetivos dessa proposta de revisitar os Jê segundo essa abordagem contemporânea são: 1) o mapeamento e a compreensão das redes de relações existentes entre os diferentes povos Jê; 2) a reinserção dos Jê no cenário comparativo da etnologia das terras baixas sul-americanas; 3) O preenchimento de uma lacuna na profícua etnologia jê, no que tange ao tema das redes de relações e dos sistemas regionais ameríndios.

\section{Como e onde circula?}

pesquisando entre os Apinayé, e Júlio Cezar Melatti, entre os Krahô (GORDON, 1996). Houve certa demora na publicação dos resultados do projeto, que só saiu em livro em 1979, sob o título de Dialetical Societies. Contudo, em que pese a demora na publicação, o projeto foi de suma importância para o estabelecimento de questões centrais que marcaram certas especificidades da etnologia jê no panorama mais amplo da ainda incipiente etnologia ameríndia de então.

${ }^{5}$ O Projeto Redes de Relações Indígenas no Brasil Central, coordenado pelos autores do presente texto, está vinculado ao Núcleo de Assuntos e Estudos Indígenas (NEAI) da Universidade Federal do Tocantins (UFT). Atualmente o projeto conta com a participação de oito pesquisadores de povos Jê do Brasil Central. 
Os pressupostos teóricos e metodológicos que embasam o presente trabalho são inspirados na ideia de configurar áreas etnográficas de pesquisa, tal como o desenvolvido por Júlio César Melatti (2011a). Trata-se, segundo o autor, de situar os coletivos indígenas das terras baixas sul-americanas em áreas etnográficas "como recurso didático que permita relacioná-las com situações específicas e ao mesmo tempo chamar atenção para sua diversidade cultural" (MELATTI, 2011 b, p. 01). Em linhas gerais, tal recurso didático se apresenta em parte como um exercício de reformulação do clássico conceito de Áreas Culturais - levado a cabo por Steward nos longos volumes do Handbook of South American Indians. De fato, se Melatti já sublinhava alterações do conceito de área cultural na própria obra de Steward quando, por exemplo, foi substituído pelo conceito de tipo cultural, por meio de "um deslocamento de interesse dos traços culturais para as relações sociais e [respectivamente] do difusionismo para o evolucionismo" (MELLATI, 2011 a, p. 2-3), a sua retomada atual exige a articulação ainda mais radical entre aspetos socioculturais e históricos.

Sabe-se que um longo debate se seguiu à proposta de Steward acima mencionada. Assim, por exemplo, Eduardo Galvão reformulou o conceito de áreas culturais para o contexto dos grupos indígenas brasileiros, avançando em muito nas definições propostas por Steward. Este avanço, seguindo Melatti, se configura na escolha de critérios inovadores para definir uma área cultural. Dentre eles, Melatti destaca o limite temporal de validade da definição de áreas culturais, estabelecido por Galvão em sessenta anos, compreendendo o período de 1900 a 1959; a opção por enfatizar os contatos intertribais e, também, os contatos com a sociedade dita nacional. Embora respeite estas escolhas, Melatti ressalta dois sérios problemas na forma de qualificar esses critérios de definição utilizados por Galvão:

Um deles se evidencia na leitura da apresentação esquemática de cada área. As culturas incluídas em cada uma delas são como que subdivididas em seus componentes de modo a serem utilizados na caracterização da área. Esta, porém, toma o aspecto de uma mera lista de traços culturais, sem que se logre relacioná-los de modo a obter uma totalidade mais 
André Demarchi e Odilon Morais - Redes de relações indígenas no Brasil Central...

ampla que seria a área. A mesma leitura nos põe diante de outro problema, que é a interpretação que Galvão faz dos exemplos de contato intertribal, tomados sempre como processos de homogeneização cultural, isto é, sempre considera o contato entre duas ou mais sociedades indígenas sob o ponto de vista da aceitação, por umas, das culturas das outras, ainda que em longo prazo, nunca supondo a possibilidade de se manterem diferentes, numa associação simbiótica (MELATTI, 2011a, p. 03).

Essas considerações feitas por Melatti nos interessam particularmente, não apenas porque seguimos suas definições do conceito de área etnográfica, mas também porque oferecem uma crítica profunda aos estudos difusionistas, com sua predileção pelas origens comuns e pelos processos de aculturação. Em defesa de Galvão, podese afirmar, contudo, que este era o espírito de seu tempo, o arcabouço teórico que embasava a incipiente etnologia brasileira nos anos de 1950. Mas mesmo com essa insistência no difusionismo, que Melatti quer evitar, o esforço de Galvão é notável. Tanto que as inovações propostas por Melatti são reformulações do seu trabalho, atualizações do espírito daquele tempo no qual estavam em destaque os estudos aculturativos.

Negando a mera enumeração de traços culturais e suas exceções, as preocupações com a uniformidade cultural e a consequente uniformização como resultado inexorável do contato entre as culturas, Melatti propõe, em um trabalho anterior (1979), um novo conceito para superar essas limitações: os polos de articulação indígena. Segundo o autor,

a proposta consistia em cartografar as sociedades indígenas e as cidades que lhes estão próximas como se fossem pontos, e unir esses pontos por linhas de espessuras diversas conforme o número de relações que os ligassem: intercasamentos, trocas comerciais, convites para ritos, procura dos serviços de médicos e feiticeiros, participações em eleições, procura de escolas, etc. Preterindo assim a uniformidade e a homogeneização cultural em favor de uma maior atenção nas relações sociais, poderíamos apontar os laços das sociedades indígenas entre si e com as sociedades nacionais, mantendo cada qual como uma totalidade sócio-cultural. Em outras palavras, cada 
sociedade indígena, não seria agrupada com outras que se parecem com ela, mas sim com aquela que partilha sua vida social (MELATII, 2011a, p. 04-05).

Se este conceito abre um novo leque de possibilidades para definir, agora, áreas de convivência interétnicas e não mais de meras similaridades culturais, Melatti sabe que, ao mesmo tempo, ele também coloca limitações. A opção pelos polos de articulação "privilegia o contato interétnico em detrimento de outros problemas" (MELATTI, 2011 a, p. 05). Para ampliar ainda mais o leque de suas definições, Melatti propõe "escolher uma divisão que leve em consideração uma ampla gama de aspectos, o que nos conduz a uma solução de compromisso entre as áreas culturais de Eduardo Galvão e os polos de articulação" (MELATTI, 2011 a, p. 05).

Em seu compromisso com Galvão, Melatti considera, então, os seguintes critérios: o estabelecimento "de um limite temporal da validade da divisão, que poderia ser os últimos 50 anos"; "a classificação linguística [para] levar em conta origens comuns e conexões no passado" (MELATTI, $2011 \mathrm{a}$, p. 5) e as considerações sobre meio ambiente, além, é claro, da consideração do contato das sociedades indígenas entre si e com as sociedades nacionais.

Afora o pressuposto temporal da validade da divisão em áreas, os outros quatro critérios escolhidos por Melatti estão dispostos na figura abaixo, que compõe um modelo de definição assumidamente arbitrário, mas não menos interessante.

$O$ ponto $U$ delimita uma unicidade cultural hipotética, tomada como ponto de referência para a explicitação de um modelo relacional gradativo, baseado nos pesos atribuídos aos critérios elencados e levados em conta para definir tal unicidade em determinada área etnográfica. Se se segue a linha vertical, que configura a reta UO $(O$, de origem), a ênfase recai sobre a proximidade linguística que, "do centro para a margem", relaciona "sociedades falantes do mesmo dialeto, da mesma língua, de línguas da mesma família, de línguas do mesmo tronco, de diferentes troncos e assim por diante" (MELATTI, $2011 \mathrm{a}, \mathrm{p}$. 6). A linha UA (A, de ambiente), por sua vez, privilegia a inserção de tal unidade hipotética $U$, vivendo em determinado ambiente $A$, em conjunto ou não com outros grupos sociais. O segmento UT ( $T$, de tribais, 
intertribais) leva em conta as relações intertribais, "de um máximo de relações envolvidas no intercâmbio para um mínimo" (MELATTI, 2011a, p. 6). Por fim, Melatti destaca o segmento UC (C, de cidade), que envolveria as relações gradativas, de um máximo para um mínimo de relações, com as sociedades nacionais.

Figura 1: Critérios de delimitação de uma área etnográfica.

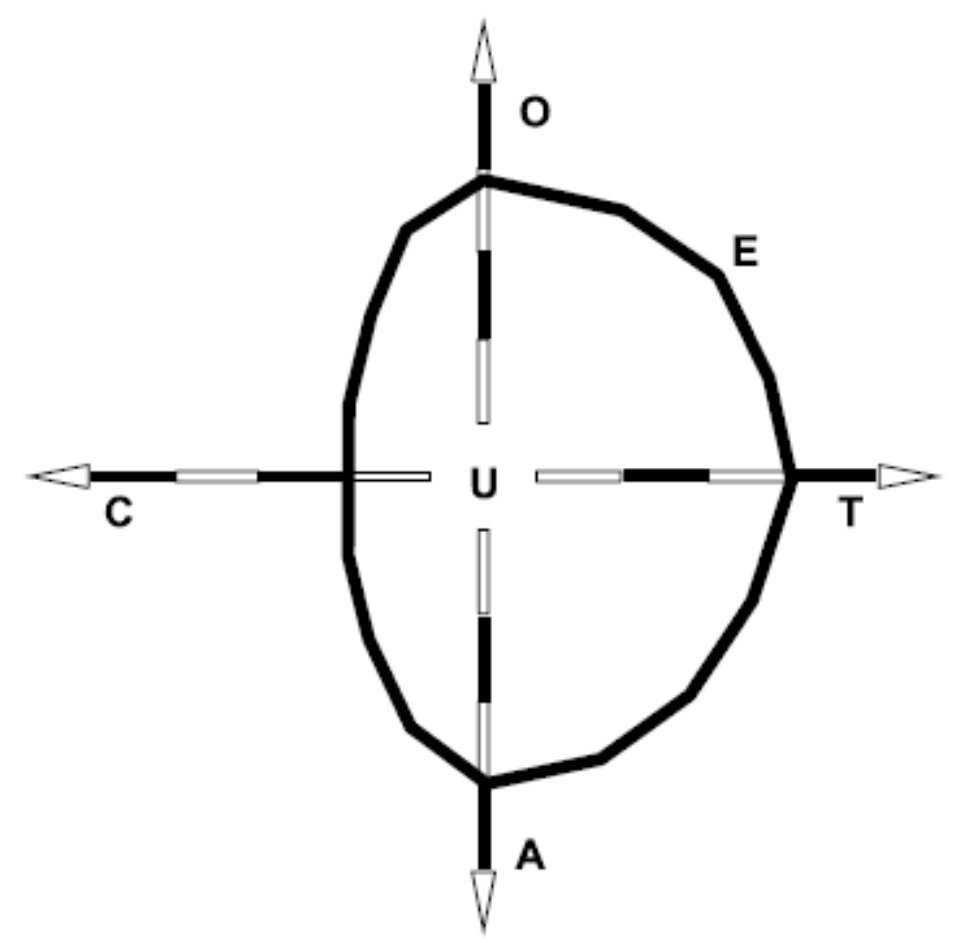

Fonte: Melatti (2011a, p. 06).

Como afirma o autor, seria relevante considerar as relações de interdependência entre cada uma das retas compostas pelos quatro critérios elencados no diagrama.

O eixo CUT não se compõe de dois seguimentos completamente autônomos, uma vez que as relações entre índios e civilizados podem servir de veículo para relações intertribais e vice-versa (...). Por sua vez, o eixo OUA, também não se compõe de segmentos completamente independentes, pois, como mostrou Roque Laraia, as sociedades que falam línguas do tronco Tupi, tendem a ocupar áreas cobertas por florestas (MELATTI, 2011a, p. 06-07). 
Por último, Melatti destaca o ponto E (E, de etnólogo, etnógrafo), que insere o elemento da arbitrariedade de qualquer definição de áreas culturais. Neste sentido, Melatti é taxativo:

Em vista do alto grau de arbitrariedade do qual não se
pode escapar, a melhor solução será assumi-la. Em
vez de falar em 'áreas culturais', melhor será dizer
áreas 'etnográficas', de modo a acentuar que elas não
existem inteiramente por si mesmas, mas que o
pesquisador é quem, em última análise, as delineia
(MELATTI, 2011a, p. 07).

Tal indefinição, assumida como parte do processo de convencionalização de uma área etnográfica, torna-se particularmente patente quando Melatti se dispõe a comentar o caso da área TocantinsXingu, que nos interessa particularmente porque configura a área de interesse da presente proposta. Ainda mais interessante é a afirmação do autor de que "no traçado desta área nenhum dos quatro critérios que considerei no texto introdutório deste trabalho foi aplicado em sua inteireza, ainda que por motivos justificáveis" (MELATTI, $2011 \mathrm{~b}$, p. 01). Quanto aos critérios do ambiente, nada mais correto do que dizer que esta área inclui tanto as populações que vivem no Cerrado (mas não todas) quanto as que vivem na Floresta Amazônica, como os Kayapó, que, a despeito desta diferença de habitat, possuem consagradas proximidades com os povos Timbira do Cerrado. Em relação à origem, tal delimitação inclui praticamente todos os falantes das línguas da família Jê, excluindo, contudo, os Jê Meridionais (kaingang e xokleng) e os Suyá do Alto Xingu, mas agrupando, de outra feita, os Bororo e Karajá, do tronco Macro-Jê e, por força da proximidade, dois grupos Tupi, os Tapirapé e os Avá.

Quando encontramos os critérios do "contato com os civilizados" e dos "contatos intertribais", os elementos que nos interessam aqui começam a ficar mais claros, sobretudo porque Melatti concede a eles menor peso na definição desta área etnográfica. Quanto ao primeiro desses critérios, o contato com a sociedade nacional, o autor afirma que "diferentes centros regionais atraem os índios desta área em várias direções: Altamira, Marabá, Imperatriz, São Luís (para o norte); Cuiabá, para o oeste; Goiânia, Brasília, para o sul" (MELATTI, 2011 b, p. 01). 
A proposta do autor, considerando esses critérios na delimitação de áreas etnográficas, parece conceder maior peso nas "relações intertribais", sendo uma variável central para incluir ou excluir um determinado grupo de determinada área etnográfica:

[...] minha intenção é, ao invés de excluir de uma mesma área sociedades indígenas, ou até segmentos de uma mesma sociedade, ainda quando situadas em países sul-americanos distintos, apenas porque "puxadas" por centros urbanos localizados em direções opostas, dar maior peso às relações intertribais (MELATTI, 2011a, p. 07).

Quando se fala em relações interétnicas na etnologia brasileira, geralmente se destaca o estudo do contato entre índios e brancos, isolando-as das relações historicamente estabelecidas entre os grupos indígenas (LIMA e CÓRDOBA, 2011). Influenciados pela matriz dos sistemas interétnicos proposta por Cardoso de Oliveira (1976), uma profusão de estudos sob o rótulo de "relações interétnicas" investiram em interpretações de trajetórias independentes de acomodação a situações históricas determinadas pelos processos de expansão do Estado e sociedade brasileira. Igualmente, a presente proposta inclui em seus objetivos a compreensão dos processos de objetivação da cultura e da formação da "autoconsciência étnica" no contexto das relações entre os "índios e o mundo dos brancos", tal como analisado por Jackson (1991 e 1994), Turner (1991) e Albert e Ramos (2002). De fato, há mais de vinte anos Turner (1991, p. 79) já chamava atenção para

[...] o desenvolvimento nos povos indígenas da autoconsciência étnica, e com ela a habilidade para objetivarem-se a si mesmos, da perspectiva de diferentes elementos e opinião nacional, com possibilidade de manipular estas imagens em seu próprio interesse... (TURNER, 1991, p. 79).

Expandindo as questões colocadas por esses autores, busca-se também a compreensão de como certas imagens e representações da indianidade circulam entre redes de relação intertribais e interétnicas em situações relacionais orientadas pela aliança, mas, ao mesmo tempo, muito influentes nas formas de representação e aproximação histórica com os "brancos". A inserção de uma perspectiva sobre as historicidades 
nesta discussão é, assim, de maior relevância.

Recentemente, Carneiro da Cunha (2009) propôs uma distinção entre cultura sem aspas e cultura com aspas, refletindo a relação entre a "cultura em si" e a "cultura para si". Com efeito, a autora propõe uma interessante questão para a pesquisa etnográfica: "quais são os processos, as questões e as transformações implicadas no ajuste e na tradução da categoria importada de 'cultura' por povos periféricos?" (CARNEIRO DA CUNHA, 2009, p. 313). Para nosso interesse, a questão passa a ser: como se dá a indigenização da indianidade no contexto das "relações interétnicas"? Considerando que a etnologia sul-americana tem se dedicado extensamente a analisar as representações da indianidade em situações de contato entre "índios e brancos", cabe-nos focar, aqui, em como se dá a indigenização da indianidade no contexto do intercâmbio de representações sobre o "ser índio" em situações de contato entre diferentes grupos indígenas.

Nos inspiramos também nos esforços analíticos e etnográficos do projeto temático Sociedades Indígenas e suas fronteiras na Região do Sudeste das Guianas (GALLOIS, 2005), os quais apontam para o cuidado de

[...] superar o recorte étnico, evitando a limitação ao estudo das relações no interior de uma suposta etnia, um conceito altamente problemático tanto nas Guianas com em outros lugares. Pelo contrário, seria necessário frisar as diferenças internas aos conjuntos designados como étnicos e apontar os aspectos históricos e contemporâneos que os caracterizam [...] (GALLOIS, 2005, p. 18).

Os dados etnográficos apresentados para o caso guianense permitiram rever a operacionalidade do recorte étnico, chamando a atenção para "outro campo para a observação: quais os impactos da intensificação da comunicação e do intercâmbio entre visões sobre essas sociedades e visões dessas sociedades sobre si mesmas" (GALLOIS, 2005, p. 18).

Assim, se nas Guianas, no Noroeste Amazônico, no Alto Xingu, no "macroconjunto pano" ou, ainda, para os Aruaque subandinos, passouse cada vez mais a adotar uma perspectiva centrada nos "sistemas regionais" (GALLOIS, 2005; VIVEIROS DE CASTRO, 2002, p. 333; 
André Demarchi e Odilon Morais - Redes de relações indígenas no Brasil Central...

ANDRELO, GUERREIRO e HUGH-JONES, 2015), os povos de língua jê estiveram à margem destes recortes de caráter regional, isto é, atentos às articulações "intertribais e interétnicas" 6 . É essa lacuna que iniciamos a preencher com o presente artigo, comparando, na parte que se segue, a circulação de pessoas, artefatos e rituais em diferentes grupos Jê.

\section{O que circula?}

O caso dos Krahô (Mehi), descrito por Melatti (1970, 1978 e $2011 \mathrm{~b}$ ), é um bom exemplo da existência de dados etnográficos residuais sobre as redes de relações existentes entre os grupos Jê. Embora não tenha sido objeto de análise do autor, em vários momentos de sua obra ele destaca que os moradores das aldeias krahô mantinham relações de casamentos e cerimoniais principalmente com os Canela da aldeia Porquinhos (MA), mas também com os Apinajé, os Xerente e com os negros descendentes de quilombos7. Com os Xerente (que não são timbira), os Krahô, por exemplo, têm estabelecido relações duradouras que se articulam em torno de casamentos interétnicos, nos quais indivíduos xerente vão morar nas aldeias krahô depois de casados.

Melatti (1970, p. 50 e 1978, p. 31-32) levanta a hipótese de que o lugar dos Xerente na sociedade krahô estaria vinculado à altivez dos primeiros em relação ao contato com os "civilizados". Ao comparar a relação dos Krahô com outros grupos Timbira (Apaniekrá e Pucobiê), nota que estes contribuíram com o que o autor chama, seguindo uma problemática levantada por Galvão (1979), de "aculturação intertribal" via a adoção de ritos e cânticos. Explica-se assim que o "contato" com os grupos conhecidos como Timbira Orientais (Apaniekrá, Pucobiê, Krikati e Ramcocamekrá) favoreceram os Krahô em termos da proximidade da língua e do sistema social. Segundo Melatti (1978, p.

\footnotetext{
${ }^{6}$ Por outro lado, quando se atenta para comparações desde uma perspectiva da organização social ou da cosmologia, os povos de língua jê sempre ocuparam lugar central na paisagem etnológica das terras baixas da América do Sul (OVERING, 1981 e 1983/84; RIVIÈRE, 2001; VIVEIROS DE CASTRO, 1986, p. 30; MAYBURY-LEWIS, 1979), vide o trabalho seminal do Projeto Harvard-Brasil Central e todas as suas consequências para os desenvolvimentos da etnologia ameríndia.

${ }^{7}$ Sobre a relação dos Krahô com os quilombolas, ver Melatti (2015).
} 
André Demarchi e Odilon Morais - Redes de relações indígenas no Brasil Central...

32), "o contato com os Xerente, por outro lado, parece agir no sentido oposto ao do contato com tribos Timbira Orientais: através dos Xerente os Krahô são levados a adotar costumes dos civilizados".

Mas estamos aqui a falar de "aculturação intertribal" ou de diferentes modalidades de relações sociais? A julgar pelo relato de um informante de Melatti, "o Xerente é um povo bom, mas é muito zangado. Os Krahô são um povo alinhado e manso. O Krahô ainda tolera alguma coisa" (MELATTI, 2009, p. 48). Deste modo, seria na intersecção entre os fatos do "contato interétnico" e dos conhecimentos xerente sobre essa relação específica que eles teriam, digamos, um determinado lugar na sociedade krahô.

Se, na relação com os Xerente, os Krahô "são levados a adotar costumes dos civilizados", é, por outro lado, no convívio com os Xerente que os Krahô têm acesso a uma forma de conhecimento mais altivo e destemido para com os "civilizados". O mesmo autor ainda nos dá pistas sobre esta forma de relação ao analisar a personalidade do líder do movimento messiânico krahô:

José Nogueira se casou com uma mulher Xerente, mais velha do que ele e parenta do chefe da aldeia de Serrinha, João Noleto. A mulher já tinha um filho, Joaquim, e parece que, nos primeiros anos da união, tinha uma certa ascendência sobre o marido. Ela é que ensinou a lidar com os civilizados (MELATTI, 1972, p. $54)$.

Trabalhando com esses dados residuais da obra de Melatti, Morais (2015) afirma que existe entre os dois grupos uma circulação intensa nas "imagens de ser índio", conceituada pelo autor como um processo de "inter-indianidade" no qual os dois grupos intercambiam imagens elaboradas sobre si e sobre o outro. No caso em tela, afirma Morais seguindo Melatti, enquanto os Xerente veem os Krahô como "índios de verdade", ou seja, que possuem traços culturais performativos (como os rituais, o corte de cabelo, a corrida de toras, aldeia circular) passíveis de serem reconhecíveis como "tradicionais"; os Krahô, como vimos, veem os Xerente como exímios interlocutores com a sociedade nacional, verdadeiros diplomatas na arte de tecer relações e capturar simbolicamente os indivíduos não indígenas e seus objetos socialmente 
valorizados. Segundo Morais, um aprendizado mútuo tem balizado as relações entre os dois grupos, uma vez que os Krahô aprendem a lidar com os brancos por meio do contato com os Xerente, e, por sua vez, estes últimos retomaram seus rituais e atividades cerimoniais através do contato com os Krahô e suas tradições.

Também nos trabalhos de Nimuendaju (1985) e DaMatta (1976) sobre os Apinajé, registra-se, mesmo que de modo lateral, a presença de indivíduos das etnias Xerente, Krahô e Krikati convivendo em aldeias daquele povo. É também recorrente entre os Apinajé a menção a indivíduos kayapó presentes entre eles. Sabe-se que, durante o processo conflituoso de demarcação do território apinajé, uma delegação de guerreiros kayapó, xerente e krahô aportou na cidade de Tocantinópolis para pressionar as autoridades em favor da demarcação do território (MORAIS, 2007; SCHIAVINI, 2006). Contam os que vivenciaram esse evento que um grupo de guerreiros dessas etnias não voltaram às suas aldeias, como, por exemplo, alguns xerente (que conhecemos) e que ali permaneceram desde esse evento, casando entre os Apinajé.

Entre os Kayapó, que estão na borda mais ocidental da mesopotâmia Tocantins-Xingu, e onde as temáticas das redes de relações foram mais exploradas pelos seus etnógrafos recentes, destaca-se a existência de extensas redes de relações que abrangem a circulação/apropriação de pessoas, cantos, objetos e formas rituais de outros povos Jê e não Jê (LEA, 1986; VERSWIJVER, 1992; GORDON, 2006; COHN, 2005; DEMARCHI, 2014). As diversas formas de apropriação constituídas pelos Mebengôkre estão principalmente relacionadas à guerra - como forma de captura de pessoas e partes agentivas do inimigo como enfeites e matérias-primas, principalmente miçangas de vidro - e ao ritual, como forma de redistribuição social e cerimonial da beleza capturada dos outros.

Os Kayapó são também famosos por se apropriar de rituais inteiros apreendidos de outros grupos indígenas (e não indígenas) que visitam suas aldeias e que são visitados pelos Kayapó (VIDAL, 1977; GORDON, 2006; COHN, 2005). Um exemplo recente que nos dá uma dimensão de até onde as redes de relações podem alcançar é o do ritual Yna Yna, absorvido pelos Kayapó de um pequeno grupo de indígenas 
André Demarchi e Odilon Morais - Redes de relações indígenas no Brasil Central...

peruanos que visitaram uma de suas aldeias no ano de 2014 , durante a realização de uma feira interétnica de trocas de sementes. A intensidade pela qual os Kayapó se dedicavam a este ritual foi documentada no filme de mesmo nome realizado pelo indígena Bepunu Kayapó ${ }^{8}$. No filme, diversos grupos de homens e mulheres dançam sincronizadamente os passos característicos dos índios peruanos. A música também característica dos indígenas do Peru ecoa de uma enorme caixa de som, localizada na casa dos homens, ao centro da aldeia circular. Alguns meses depois, um indígena de outra aldeia postou, no site de relacionamento Facebook, trechos de uma gravação de celular onde cenas da festa peruana eram performadas por entusiasmados dançarinos de outra aldeia kayapó. O ritual Yna Yna havia se espalhado. Essas intensas redes de relações imagéticas e contemporâneas nos fazem pensar sobre a forma como os diferentes grupos indígenas se veem uns aos outros ao longo do tempo.

Eduardo Nunes (2013), em sua etnografia sobre os Karajá, demonstra como os objetos cerimoniais, pinturas corporais e até rituais capturados e apreendidos de outros grupos são incorporados à cultura karajá, a ponto de, com o passar do tempo, terem apagados os registros de que um dia tenham sido de outros povos. O apagamento das origens estrangeiras das pessoas e coisas capturadas do exterior expõe as diversas facetas (pragmáticas, históricas, conceituais) com as quais os Karajá traduzem e produzem a sua própria noção de cultura.

Entre os Canela (Ramkokamekra) do Maranhão, uma descoberta recente, em meio a um estudo sobre o ritual de iniciação masculina Pepkahak, colocou questões importantes para o tema das redes de relações, principalmente no que ele pode apresentar enquanto potencial crítico para outros temas clássicos da etnologia e da antropologia, como, por exemplo, o debate em torno da definição de grupos étnicos em unidades irredutíveis (WAGNER, 2010; VIVEIROS DE CASTRO, 1999; VIEGAS, 2007). A pesquisa de Soares (2015) demonstra como, em um determinado momento do ritual Pepkahak, todos os "povos" que foram agrupados sob o etnônonimo Ramkokamekra se apresentam publicamente, demonstrando a constituição múltipla desse coletivo, constituído por "povos" em estreitas e profundas relações históricas de

${ }^{8}$ Título: Yna Yna. Direção: Bepunu Kayapó. Duração: 60 min. Ano: 2014. 
aliança e parentesco. Para corroborar essa questão, durante o VI Seminário Timbira, realizado na cidade de Carolina (MA), o pesquisador canela Ricardo Kaperekô desenhou no papel a configuração desses povos durante o ritual Pepkahak.

Figura 2: A configuração dos povos que compõem os Canela durante o ritual Pepkahak.

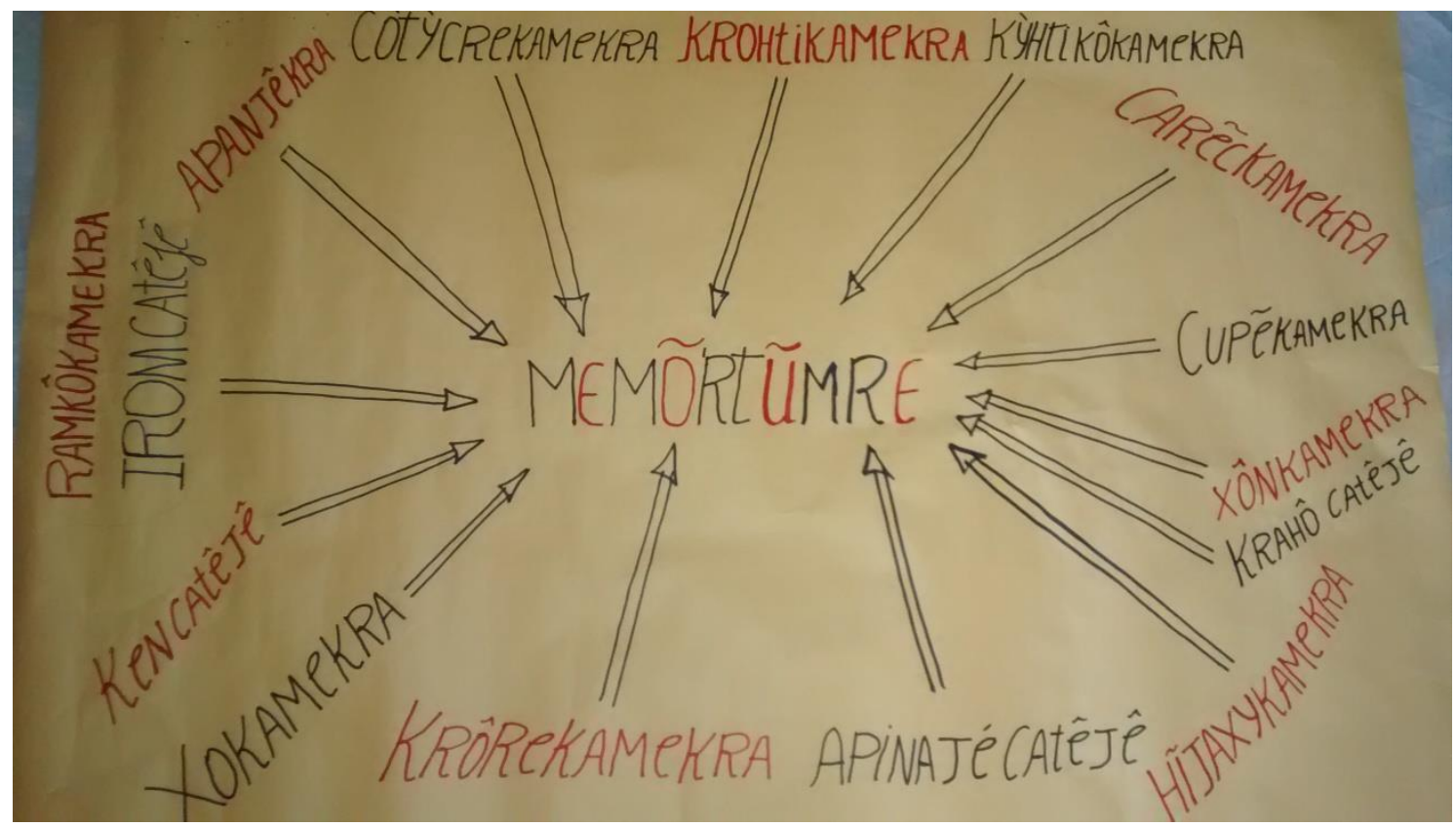

Fonte: Elaborado por Ricardo Kaperekô Canela, em 2015.

Algo semelhante ocorre entre os Gavião Pyhcopcatiji, pesquisados por Melo (2015), onde uma profusão de etnônimos foi transmitida pelos indígenas quando o pesquisador lhes fez perguntas como "quem são vocês" e "de onde vocês vieram". A existência de diferentes povos na constituição daquilo que se convencionou chamar de "povo" ou "grupo étnico" vai ao encontro das críticas que têm sido feitas na antropologia ao conceito de sociedade enquanto uma totalidade autocontida (STRATHERN, 2006; VIVEIROS DE CASTRO, 2002; COELHO DE SOUZA, 2002) e também ao próprio conceito de "grupo social" enquanto unidade fechada sobre si mesma (WAGNER, 2010). Essas ideias são importantes para questionar, enfim, a imagem dos povos Jê (COELHO DE SOUSA, 2002) enquanto povos fechados e centrípetos, como ficaram marcados na etnologia ameríndia (FAUSTO, 2001; OVERING, 1981).

As diversas evidências empíricas apresentadas acima, muitas 
vezes residuais nas etnografias clássicas, parecem refletir outra imagem do Brasil Central, como uma área etnográfica articulada em diferentes nexos regionais e, por sua vez, com diferentes modalidades de articulações étnicas entre os grupos indígenas da região. A descrição e análise desses nexos, articulações e redes de relações (matrimoniais, cerimoniais, imagéticas, políticas) produzidas pelos diversos povos desta vasta região é uma tarefa que começamos a realizar através de casos etnográficos específicos, como as pesquisas em andamento acima mencionadas 9 . Objetivamos, assim, ao focalizar essas diversas redes de relações, contribuir para o preenchimento dessa lacuna na etnologia dos povos Jê, visando à reinserção comparativa desses povos no cenário da etnologia das terras baixas sul-americanas.

\section{Considerações Finais}

Para o caso das etnografias sobre os grupos Jê, como descrevemos acima, apenas recentemente tem havido uma preocupação sistemática com a descrição e análise das relações entre os diversos grupos indígenas habitantes do Brasil Central, mesmo que seja notória a presença de dados nas etnografias sobre a circulação de pessoas, coisas e rituais entre os diferentes povos dessa região. Deste modo, nota-se, por um lado, que se esses dados aparecem de modo residual em etnografias produzidas no âmbito do Projeto Harvard-Brasil Central; por outro, nas etnografias recentes, eles são tomados como ponto de partida ou mesmo como foco das pesquisas. Trabalhos como o de Coelho de Souza (2002), em seu esforço comparativo de toda a literatura jê, demonstram uma infinidade de relações e transformações de relações sociais, mitológicas, econômicas, cosmológicas e também de parentesco, de aliança e de guerra existentes entre os diversos grupos Jê e para além do Brasil Central. Paradoxalmente, Coelho de Souza, em seu trabalho monumental, nos ensina que não existe uma "identidade jê" constituída pelos povos que são assim denominados.

\footnotetext{
${ }^{9}$ É importante ressaltar que os trabalhos recentes debatidos neste tópico são resultados de pesquisas cujos realizadores se reuniram no Simpósio de Pesquisas Pós-Graduadas Os Jê revisitados: Redes de relações indígenas no Brasil Central, realizado no ano 2015 durante o $39^{\circ}$ Encontro Anual da ANPOCS (Associação Nacional de Pós-Graduação e Pesquisa em Ciências Sociais).
} 
André Demarchi e Odilon Morais - Redes de relações indígenas no Brasil Central...

Aprendemos que a "unidade étnica" encapsula uma série de variantes distintas de formas de organização social, muitas vezes tendentes às fissões contínuas que articulam e rearticulam isso que se denomina "sociedade" ou "etnia" ou "grupo social" (COELHO DE SOUZA, 2002; STRATHERN, 2006; WAGNER, 2010). Todos os casos etnográficos pesquisados exaustivamente pela autora e também todo o seu esforço comparativo-analítico de fôlego vai no sentido de desconstruir e reconceituar essas categorias analíticas (sociedade, etnia, grupo social) a partir de uma crítica etnograficamente embasada. Após esse trabalho monumental, não podemos dizer senão que aquilo que denominamos "jê" aqui neste trabalho é apenas uma forma consciente de tratar de coletivos que possuem características similares e, mais importante, que tecem historicamente profundas redes de relações entre si, mas que jamais reivindicaram para si (e em si) uma pretensa "identidade étnica jê".

Com isso em mente poderíamos configurar pelo menos dois circuitos de relações supralocais articuladas em rede: o primeiro seria o caso dos povos indígenas Timbira, em que padrões de introversão/extroversão, influenciados por circunstâncias históricas específicas, marcariam sua socialidade. Nessa primeira configuração, teríamos de um lado os Ramkokamekra (Canela), operando uma introversão na qual as diferenças são internas e reorganizadas no plano aldeão (ver imagem acima); e de outro, os Krahô e Apinajé, também incorporando estrangeiros de outras aldeias timbira, dos Xerente (Akwen) ou mesmo não índios, mas fundamentalmente diferente do caso ramkokamekra, operando a extroversão através de um intenso processo de segmentação das unidades aldeãs vivenciado desde pelo menos o início do presente século.

O segundo caso é o processo de intensa fusão e cisão vivida entre si pelos diversos grupos Kayapó ao longo dos dois últimos séculos. Neste processo, foram travadas relações guerreiras tanto entre si pelos grupos Kayapó quanto contra outros povos falantes de língua tupi e que, atualmente, parecem continuar através de outras formas de relações ritualizadas marcadas pela incorporação de bens materiais e imateriais (DEMARCHI, 2014). Esses dois casos são mais variações de modalidades de relações do que propriamente tipos determinados de 
André Demarchi e Odilon Morais - Redes de relações indígenas no Brasil Central...

articulações sociais supra-aldeãs. Nesse contínuo de variações, há outros casos, como o dos Xerente, em que as relações com os não índios parecem ser mais intensas (e desejadas) do que os casos acima apontados (RAPOSO, 2009), mas onde também é notável uma migração de indivíduos e/ou grupos familiares xerente para aldeias timbira krahô, apinajé, krikati, paracatejê (MORAIS, 2007). Como os Krahô e os Apinajé, os Xerente têm vivenciado também um importante processo de segmentação das unidades aldeãs, chegando mesmo a ser um casolimite quando comparado aos dois primeiros povos indígenas: os Xerente chegam ao presente momento somando cerca de 64 aldeias para um contingente populacional estimado em 4 mil pessoas; entre os Krahô e os Apinajé, cujas respectivas populações não parecem ultrapassar 2.800 indivíduos, conta-se atualmente pouco mais de 32 aldeias.

Como um resultado inicial da análise de alguns fragmentos dessas redes de relações, pode-se destacar que elas não se "constituíram nem historicamente, nem na atualidade - [como] circuitos rígidos, seja etnicamente encerrados, seja exclusivos a determinados percursos e territórios", algo já observado para o caso das redes de relações estabelecidas pelos povos indígenas da região guianense (GALLOIS, 2005 , p. 13). Assim, a partir desses resultados iniciais, buscamos aprofundar a análise das modalidades de relações aqui delineadas, configurando uma paisagem centro-brasileira menos caracterizada pelo suposto fechamento destes povos indígenas, seguindo, assim, as pistas deixadas pela análise de Coelho de Sousa (2002).

\section{Referências bibliográficas}

ALBERT, Bruce. Temps du sang, temps des cendres: représentation de la maladie, système rituel et espace politique chez lês Yanomami du sud-est (Amazonie brésilienne). Nanterre: Université de Paris X, 1985.

ALBERT, Bruce; RAMOS, Alcida R. Pacificando o branco: cosmologias do contato no Norte-Amazônico. São Paulo: Editora UNESP, 2002. 
André Demarchi e Odilon Morais - Redes de relações indígenas no Brasil Central...

ANDRELO, Geraldo; GUERREIRO, Antônio; HUGH-JONES, Stephen. Space-time: transformation int the upper Xingu and upper Rio Negro. Revista de Sociologia e Antropologia, Rio de Janeiro, v. 5, n. 3, p. 699-724, 2015.

BARATA, Maria Helena. Os Pukobyê e os Kupên: analise de um drama. 1981. 154 f. Dissertação (Mestrado em Antropologia Social) - PPGAS, UNB, Brasília, DF, [1981].

Tupi-Guarani e Jê Timbira: Articulações Étnicas em Processo. 1999. 403 f. Tese (Doutorado em Antropologia) - PPGAS, UnB, Brasília, DF, [1999].

CARDOSO DE OLIVEIRA, Roberto. Processo de articulação étnica. In: Identidade, Etnia e Estrutura Social. São Paulo: Pioneira, 1976. p. 5373.

CARNEIRO DA CUNHA, Manuela. 'Cultura' e cultura: conhecimentos tradicionais e direitos intelectuais. In: \& Naify, 2009. p. 311-373.

COELHO DE SOUZA, Marcela. O traço e o círculo: o conceito de parentesco entre os Jê e seus antropólogos. 2002. 276 f. Tese (Doutorado em Antropologia) - PPGAS, Museu Nacional, UFRJ, Rio de Janeiro, [2002].

COHN, Clarice. Relações de Diferença no Brasil Central: os Mebengokré e seus Outros. 2005. 185 f. Tese (Doutorado em Antropologia) - PPGAS, USP, São Paulo, [2005].

DAMATTA, Roberto. Um mundo dividido: estrutura social dos índios Apinayé. Petrópolis: Vozes, 1976.

DEMARCHI, André. Kukràdjà Nhipêjx \Fazendo Cultura: Beleza, Ritual e Políticas da Visualidade entre os Mebêngôkre - Kayapó. 2014. Tese (Doutorado em Sociologia e Antropologia) - PPGSA/IFCS/UFRJ, Rio de Janeiro, [2014].

FAUSTO, Carlos. Inimigos fiéis: história, guerra e xamanismo na Amazônia. São Paulo: EDUSP, 2001.

GALLOIS, Dominique. Introdução: percursos de uma pesquisa temática. In:

(Org.). Redes de relações nas Guianas. São Paulo: Associação Editorial Humanitas/ Fapesp, 2005. p. 7-23.

GALVÃO, Eduardo. Áreas Culturais Indígenas do Brasil: 1900-1959. In:

Encontro de Sociedades: Índios e brancos no Brasil. Rio de Janeiro: Paz e Terra, 1979. p. 193-228.

GORDON, Cesar. Aspectos da organização social jê: de Nimuendajú à década de 90 . 1996. Dissertação ( Mestrado em Antropologia) - PPGAS/MN, Rio de Janeiro, [1996].

Economia Selvagem: mercadoria e ritual entre os índios Xikrin-Mebêngôkre. São Paulo/Rio de Janeiro: Ed. Unesp/ISA/Nuti, 2006. 
André Demarchi e Odilon Morais - Redes de relações indígenas no Brasil Central...

JACKSON, Jean. Being and Becoming an Indian in the Vaupés. In: URBAN, Greg; SHERZER, Joel (Org.). Nation-State and Indian in Latin America. Austin: University of Texas Press, 1991. p. 131-55.

Vaupés Indigenous Rights Organizing and the Emerging Ethnic Self. In: HILL, Jonathan (Org.). Anthropological Discourses and the Expression of Personhood in South American Inter-ethnic Relations. Bennington: Bennington College, 1994. p. 28-39. (South American Indian Studies, 3).

LEA, Vanessa. Nomes e nekrets kayapó: uma concepção de riqueza.Rio de Janeiro: Museu Nacional, 1986.

. Riquezas intangíveis de pessoas partíveis: os Mẽbêngôkre (Kayapó) do Brasil Central. São Paulo: EDUSP/FAPESP, 2012.

LIMA, Edilene C. de; CORDOBA, Lorena (Org.). Os outros dos outros: relações de alteridade na etnologia sul-americana. Curitiba: Ed. UFPR, 2011.

MELATTI, Julio Cesar. O sistema social Krahó. 1970. Tese (Doutorado em Antropologia Social) - Faculdade de Filosofia, Ciências de Letras - Universidade de São Paulo, [1970]. Disponível em: http://www.juliomelatti.pro.br/tese/teseindice.pdf. Acesso em: 27 dez. 2016.

Sociologia).

O messianismo Krahó. São Paulo: Herder, 1972. (Coleção Antropologia e

Nominadores e genitores: um aspecto do dualismo krahó. In: SCHADEN, Egon (Org.). Leituras de Etnologia Brasileira. São Paulo: Cia. Editora Nacional, 1976. p. 139-148.

Ritos de uma Tribo Timbira. São Paulo: Ática, 1978.

Pólos de articulação indígena. Revista de Atualidade Indígena. Brasília, v. 16, 1979. p. 17-28.

Índios e criadores: a situação dos Krahó na Área Pastoril do Tocantins. 2009[1967]. Disponível em: http://www.juliomelatti.pro.br/livros/livro67.pdf . Acesso em: 27 dez. 2016.

Capítulo 1: Por que áreas etnográficas? In: Áreas etnográficas da América Indígena, 2011a. p. 1-10. Disponível em: http://www.juliomelatti.pro.br/areas/01porque.pdf . Acesso em: 27 dez. 2016.

Capítulo 29: Tocantins-Xingu. In: Áreas etnográficas da América Indígena, 2011(b). Disponível em: http://www.juliomelatti.pro.br/areas/29tocxin.pdf . Acesso em: 27 dez. 2016. 
André Demarchi e Odilon Morais - Redes de relações indígenas no Brasil Central...

Entrevista com Júlio Cezar Melatti. In: DEMARCHI, André; MORAIS, Odilon. (mimeo), 2015.

MAYBURY-LEWIS, David (Org.). Dialectical Societies. Cambridge: Harvard University Press, 1979.

MORAIS, Odilon. Sawrepté: imagens do Brasil-Central. 2007. 100 f. Dissertação (Mestrado em Antropologia) - PPGAS/DAN, UnB, Brasília, DF, [2007].

Xerente e Krahó: relações de alteridade no médio Tocantins. Projeto de Doutorado. Universidade de Brasília / PPGAS/DAN, 2015.

MELO, Maycon. A inconstância da superfície: notas da expressão visual entre os Gavião Pyhcopcatiji (Timbira Orientais\MA). In: 29 $9^{\text {a }}$ Reunião Brasileira de Antropologia, 2014, Natal. Anais 29ª RBA. Brasília: Kiron, 2015. p. 01-14.

NIMUENDAJÚ, Curt. "The Apinajé". Publ. Of the Frederick Webb Hodge Anniversary Publication Fund, v. 4. Los Angeles, 1985.

NUNES, Eduardo S. Socialidades alternativas: sobre o conceito de cultura dos Karajá de Buridina. Arquivos do CMD, v. 1, 2013. p. 92-112,

OVERING, Joanna K. Review Article. Amazonian Anthropology. In: Journal of Latin American Studies, v. 13, n. 1, p. 151-65, 1981.

Elementary structures of reciprocity: a comparative note on Guianense, Central Brazilian, and North-West Amazon socio-political thought. In: COLSON, Audrey Butt; HEINEN, H. Dieter (Org.). Antropologica, v. 59-62, 1983-84.

RAMOS, Alcida Rita. Hierarquia e simbiose: relações intertribais no Brasil. São Paulo: HUCITEC, 1980.

RAPOSO, Clarisse. Produzindo Diferença: gênero, dualismo e transformação entre os Akwe-Xerente. 2009. 135 f. Dissertação (Mestrado em Antropologia Social) PPGAS/UFMG, [2009].

RIVIÈRE, Peter. O indivíduo e a sociedade na Guiana: um estudo comparativo sobre a organização social ameríndia. São Paulo: Editora da Universidade de São Paulo, 2001[1984]. (Ponta; 18).

SOARES, Lígia. "Eu sou o gavião e peguei a minha caça": O ritual Pep-cahàc dos Ràmkôkamekra/Canela e seus cantos. 2015. 322 f. Tese (Doutorado em Antropologia) PPGA, UFAM, Manaus, AM, [2015].

STRATHERN, Marilyn. O gênero dádiva. Campinas: Editora da Unicamp, 2006.

SCHIAVINI, Fernando. De longe, toda serra é azul. Brasília: Criativa Gráfica e Editora LTDA, 2006. 
André Demarchi e Odilon Morais - Redes de relações indígenas no Brasil Central...

TURNER, Terence. Da Cosmologia à História: resitência, adaptação e consciência social entre os Kayapó. Cadernos de Campo, São Paulo, v. 1, n. 1, 1991.

VERSWIJVER, Gustaf. The Intertribal relations between the Juruna and the Kayapo indians (1850-1920). Berlin: Sep. Jahrbuch des Museums für Völkerkunde zu Leipzig, 1982. v. 34.

The club fighters of Amazon: warfare among the Kayapó Indians of Central Brazil. Gent: Rijksuniversiteir te Gent, 1992.

VIEGAS, Susana. Terra Calada: os Tupinambá na Mata Atlântica do Sul da Brasil. Rio de Janeiro: 7 Letras, 2007.

VIVEIROS DE CASTRO, Eduardo. Araweté: os deuses canibais. Rio de Janeiro: Jorge Zahar Ed., 1986.

Etnologia brasileira. In: MICELI, S. (Org.). O que ler na ciência social brasileira (1970-1995). São Paulo: Org. Sumaré/ANPOCS, 1999. p. 109-223. (Antropologia, 1).

Imagens da natureza e da sociedade. In: A inconstância da alma selvagem e outros ensaios de antropologia. São Paulo: Cosac \& Naify, 2002. p. 317-345.

VIDAL, Lux. Morte e Vida de uma Sociedade Indígena Brasileira: os KayapóXikrin do Rio Cateté. São Paulo: HUCITEC/USP, 1977.

WAGNER, Roy. Existem grupos sociais nas terras altas da Nova Guiné? Cadernos de Campo, São Paulo, n. 19, p. 237-257, 2010.

Recebido em: 18/04/2016 * Aprovado em: 08/09/2016 * Publicado em: 31/12/2016 